\title{
0 ESPAÇO DOS JORNALISTAS DA ECONOMIA BRASILEIROS: GERAÇÕES, ORIGEM SOCIAL E DINÂMICA PROFISSIONAL
}

\section{THE CURRENT SPACE OF BRAZILIAN ECONOMICAL JOURNALISM: GENERATIONS, SOCIAL ORIGIN AND PROFESSIONAL DYNAMICS}

Antonio José Pedroso Neto*

Introdução: objetivos e questões teóricas e metodológicas

Este artigo apresenta uma objetivação do espaço do jornalismo econômico brasileiro (JEB) ${ }^{1}$. Para isso, foi realizada uma Análise de Correspondências Múltiplas (ACM) de 69 prosopografias de Jornalistas de Economia (JE) atuantes durante 2011. 0 trabalho é orientado por uma démarche sociológica que pesquisa a mídia a partir da "noção de campo", ou seja, entende as tomadas de posição dos JE - seus textos ou suas produções simbólicas - como produtos de suas posições em um subespaço do campo do jornalismo e da relação desse cam- po e seus subespaços com outros campos sociais (BOURDIEU, 1987a e 1994; CHAMPAGNE, 2007; DUVAL, 2004).

0 problema geral colocado para o JEB é simples: como explicar que certas informações e tomadas de posição sobre o mundo econômico são difundidas em grande escala pela maioria da mídia, enquanto outras são relevadas e/ou restam esquecidas? A hipótese geral que orienta a coleta e a análise de dados também é simples: os JE que ascenderam às posições dominantes do espaço do JEB têm origem social relativamente mais elevada que seus confrades, assim como iniciaram e mantiveram suas carreiras mais precocemente nos principais veículos

* É doutor em ciências sociais, professor e pesquisador da Universidade Federal de Tocantins e bolsista de produtividade do CNPq. ajpedrosoneto@uol.com.br

1. Agradecimentos: ao CNPq e a CAPES pelos recursos disponibilizados; ao Centro de Desenvolvimento e Planejamento Regional (CEDEPLAR) da UFMG pela residência pós-doutoral; aos colegas do Núcleo de Estudos de Sociologia Econômica e das Finanças (NESEFI) da UFSCar pelos seminários e cursos de análise geométrica de dados; aos alunos e colegas do Grupo Jornalismo e Multimídia (GJM) da UFT pelas colaborações e incentivos; aos jornalistas que colaboraram com a pesquisa; e aos colegas do seminário temático "Elites e espaços de poder" do 37o Encontro Anual da ANPOCS. 
do espaço - o que explicaria a heteronomia, ainda hipotética, dos agentes desse espaço, isto é, a produção de conteúdos mais afins com os interesses estruturais dos agentes dominantes no campo econômico.

Dada a démarche sociológica, a compreensão das diferentes produções simbólicas depende, inicialmente, do conhecimento objetivo das dimensões do espaço dos JE e de pesquisas cumulativas sobre suas tomadas de posição - análises de conteúdo e de enquadramento de seus produtos tratados como variáveis "explicadas" ou "suplementares" (LEBARON, 2009) -, sobre as estruturas do espaço das empresas de mídia, e sobre o conhecimento das práticas de recrutamento e de formação de relações com suas fontes.

A démarche mobilizada considera que os JE produzem bens simbólicos particulares - textos como colunas, editoriais, reportagens, comentários, análises - que têm influência sobre a sociedade (BOURDIEU, 1987a; CHAMPAGNE, 2000; DUVAL, 2004). Mais pontualmente, tais bens simbólicos integram e têm efeitos sobre a ordem econômica. Entretanto, dentre os produtos simbólicos possíveis, os JE operam uma seleção dos que serão publicados, ou não, e as condições em que isso ocorrerá.

Em seus textos, eles descrevem, analisam, criticam ou comentam situações de fato e, incontornavelmente, fazem isso de modo seletivo, não necessariamente em um sentido consciente, planejado, explícito, com intenções de manipulação, mas, de modo mais eficaz, em um sentido cognitivo. Ao difundirem uma e não difundirem outras doutrinas, categorias, "crenças econômicas" e "princípios cognitivos de visão e divisão de mundo" (BOURDIEU, 1997 e 2000), os JE configuram uma seleção implícita e explícita na difusão. Ao realizarem ênfases, citarem agentes sociais, incluírem vozes, e operarem enquadramentos (GOFFMAN, 1974), realizam responsabilizações, adjetivações, condenações, prescrições, etc.

Enfım, independente de serem menos ou mais objetivos - como querem os códigos deontológicos e os princípios de excelência profissional - e menos ou mais explícitos em suas tomadas de posição, os JE publicam representações, prescrições e respostas para as ações do governo, dos empresários, banqueiros, investidores, sindicatos e demais agentes econômicos. Em sintese, seus textos representam tomadas de posição e são instrumentos em lutas simbólicas. A “comunicação não é neutra” e tais produtos culturais são "expressões” de uma "política de percepção” constituinte das lutas simbólicas (BOURDIEU, 1989 e 2000).

Em outro sentido, a démarche considera que os JE agem vis-à-vis seus pares e outros agentes sociais em debates e tomadas de posição sobre os rumos e dilemas da sociedade, do Estado, do governo, da economia, etc. Atuam no campo do poder (BOURDIEU, 1996 e 1987b), ou seja, em maior ou menor medida, estão entremeados nas lutas políticas e econômicas. Agentes do campo do poder - economistas, intelectuais, banqueiros, empresários, executivos, sindicalistas, governantes, jornalistas - estão o tempo todo produzindo interpretações, representações, prescrições favoráveis ou simplesmente concatenadas com os princípios estruturantes dos seus campos de origem. Desse modo, os JE estão o tempo todo procurando "impor a visão legítima", o "conhecimento legítimo do sentido", da "significação", da "direção" dos fenômenos econômicos (BOURDIEU, 1997 e 2000). E eles atuam nesse campo, não como um grupo monolítico, mas como um grupo diferenciado internamente, como um “campo social” (BOURDIEU, 1987a). 
Em síntese, o JEB é um espaço de produção cultural e de poder. Sendo assim, é necessário lançar luz sobre os JE e tentar produzir aproximações sobre quão autônomos/heterônomos eles são, os princípios que os hierarquizam no espaço, suas relações de força. Na literatura nacional das Ciências Sociais, não há trabalhos sobre as relações entre a mídia e a economia no Brasil, ao contrário da literatura sociológica internacional, que já apresentou publicações a respeito do tema nos casos francês e norte-americano (BOURDIEU, 1994; CHAMPAGNE, 2000 e 2007; DUVAL, 2004; RIUTORT, 2000; SCHUDSON, 1995). Existem trabalhos sobre o JEB, mas eles foram realizados por jornalistas e comunicadores - marginalmente, por economistas e linguistas - e não se ocuparam com questões sobre a maior ou menor autonomia dos jornalistas e, principalmente, sobre as estruturas do espaço e as relações dos produtos simbólicos com essas estruturas.

Do ponto de vista sociológico, são as posições no espaço do JEB que contribuem fortemente para explicar como os veículos e os jornalistas tratam o mundo econômico. Sendo assim, este artigo tem uma contribuição com a literatura existente - análises históricas e estudos temáticos que tratam de períodos recentes (ABREU, 2003; ABREU E ROCHA, 2006; LENE, 2009; QUINTÃO, 1987) - a partir de uma pesquisa que procurou construir empiricamente o estado atual do espaço do $\mathrm{JEB}^{2}$. Dito de outro modo, trata-se de uma objetivação sociológica como alternativa ao senso comum autóctone, erudito e acadêmico, que recor- rentemente apresenta seus comentários, argumentos e discursos num espectro que vai da denunciação à celebração.

Em conclusão, o principal objetivo da pesquisa foi reunir o máximo possível de nomes de JE atuantes em diversas mídias: jornal, rádio, revista, televisão, agências de notícias e internet. Em seguida, levantar suas informações prosopográficas: dados sobre a trajetória e a posição ocupacional e escolar dos jornalistas e de seus pais, sobre as propriedades sociais dos jornalistas, sobre as empresas do espaço e sobre notoriedade, reconhecimento e prestígio, entre outros. E, finalmente, analisar esses dados com a ACM: objetivar o espaço do JEB.

\section{A gênese do jornalismo econômico bra- sileiro}

0 que é um jornalista da economia? 0 que é o jornalismo econômico brasileiro? Em vez de partir de um recenseamento de definições escolásticas prévias ou de definições e classificações autóctones, foi mobilizado um critério simples: a atuação prática. Tem-se como JE aqueles que atuam nas editorias de economia como empregados ou autônomos/freelances, das mídias que tratam de assuntos econômicos, sejam elas especializadas ou não - revistas e jornais impressos e online, televisão, rádio, agências de noticias, portais, etc. Na prática, os JE atuam produzindo conteúdos jornalísticos em cadernos, seções, programas, etc. nomeados pelas rubricas autóctones como economia, negócios, comércio, empresas, dinheiro, fınanças, agropecuária.

2. Os dados e as análises que constituem este artigo resultaram de pesquisas sobre mídia e economia no Brasil: "0 jornalismo econômico no Brasil: entre a economia e a política"; e "0 jornalismo econômico brasileiro e a crise financeira mundial: as posições sociais e as tomadas de posição” (cf. nota de rodapé 1). 
Em grande medida, o JEB tem um formato atual. Mas não foi sempre assim. Os textos históricos e os de cunho prosaico registram que, de fins dos anos 1960 ao início dos anos 1970, ocorreu um período de mudanças que separa o formato atual do anterior.

Até então, os jornais dedicados à economia - Gazeta Mercantil e demais jornais regionais e locais, chamados de gazeta, e de jornais do comércio em geral - tinham como conteúdo predominante a comunicação de informações comerciais e financeiras, estrito senso, e sem análise; preço e volumes da produção agrícola e industrial, cotação de bolsas, variação de câmbio, dólar, comunicados diversos e cartoriais de sociedades anônimas, limitadas e de governo, etc. Mas, desde então, ocorreram mudanças, e tais jornais, um após o outro, passaram a relatar, analisar e informar sobre a economia; as dinâmicas da economia nacional e internacional, dos setores econômicos, das empresas, dos investimentos e planos governamentais, da dívida externa, das organizações internacionais e assuntos mais relacionados ao dia a dia dos leitores, tais como poupança, taxas e serviços de condomínio, mercado de automóveis, salário (ABREU, 2003; CALDAS, 2003; KUCINSKI, 1996; NASSIF, 2003; QUINTÃO, 1987).

Nesse período, progressivamente, foram estruturadas editorias - ou reestruturadas as poucas existentes - e cadernos de economia em jornais já existentes Foram fundados ainda, novos jornais, revistas, programas de rádio e televisão dedicados a assuntos da esfera econômica. Ao mesmo tempo, começou a especialização dos jornalistas; o crescimento do pessoal, das rotinas, dos relacionamen- tos com fontes específicas e dos processos de treinamento e formação de profissionais, todos relacionados a fatos, agentes, instituições e processos da economia (ABREU, 2003; CALDAS, 2003; KUCINSKI, 1996; NASSIF, 2003; QUINTÃO, 1987).

Esse período de gênese do JEB no formato atual esteve relacionado a dinâmicas mais gerais da economia, da política e da cultura brasileira, todas elas sob fortes intervenções dos governos militares (19641985). Por um lado, esses governos atrofiaram o espaço da política com cassações, restrição de liberdades e direitos políticos, fechamento do Congresso Nacional, extinção de partidos políticos, etc. (SKIDMORE, 1988). Simultaneamente, ocorreu um atrofiamento paralelo no espaço da imprensa política com a censura de textos e a diminuição de páginas nos jornais e de jornalistas nas redações em geral (ABREU, 2003; ABREU e ROCHA, 2006; QUINTÃO, 1987). Por outro lado, no início, esses governos se legitimaram impulsionando o crescimento da economia com o "milagre econômico", o desenvolvimento industrial e a expansão do Estado (MARTINS, 1985; SKIDMORE, 1988). E, paralelamente, ocorreu a expansão do JEB com o aumento do número de páginas, editorias, cadernos e pessoal empregado nos jornais e revistas, além de novos jornais e revistas, etc. especializados em assuntos econômicos (ABREU, 2003; ABREU e ROCHA, 2006; CALDAS, 2003; NASSIF, 2003; QUINTÃO, 1987). Vale dizer que toda a expansão do JEB se deu em um contexto de ampliação da indústria cultu$\mathrm{ral}^{3}$ no Brasil, também amplamente impulsionada pelo Estado (ORTIZ, 1988).

3. Ortiz (1988) no capítulo "O mercado dos bens simbólicos" relata com detalhes a expansão exponencial do volume e dimensão da produção, distribuição e consumo dos bens simbólicos no Brasil dos anos 1970 . Essa expansão aconteceu com a presença do Estado autoritário, em aliança com o setor empresarial, fo- 
Enfım, em conjunto, a literatura nos fornece indicações claras de uma reestruturação do espaço do JEB no final dos anos 1960 e início dos anos 1970. E também nos dá indicações claras de uma consolidação nos anos 1970 como um processo que acompanhou as dinâmicas política e econômica dos governos militares e a ampliação da indústria cultural no Brasil. Vale dizer também que a literatura citada registra que esse foi o período em que entraram em cena aqueles que viriam a ser considerados os principais JE do país, muitos dos quais esta pesquisa revelou como a geração atualmente dominante - Joelmir Beting, Luís Nassif, Carlos Alberto Sardenberg, Celso Ming, entre outros.

\section{A pesquisa prosopográfica: fontes, vari- áveis e categorias}

A partir das fontes da pesquisa, da literatura específica e conforme aproximações sucessivas com o objeto, foi montado um banco de dados com duas entradas básicas: por um lado, foram construídos diferentes grupos de variáveis na tentativa de dar conta das diferentes dimensões do subespaço do JEB - as colunas; e, por outro lado, foi organizada uma lista de nomes de JE
- as linhas. Parte das variáveis e das prosopografias foram utilizadas na análise.

A determinação de uma população de JE foi delicada por alguns motivos: é um grupo fluido e sem fronteiras minimamente defınidas; não há associações profıssionais específıcas; não há registro de dados sobre esta especialização profissional - dados desagregados - em sindicatos, organismos públicos ou empresariais, e em base de dados correntemente utilizados para analisar o comportamento do mercado de trabalho - RAIS, IBGE, IBOPE, entre outros ${ }^{4}$. Resulta que foi construída uma amostra fundamentada em diversas fontes que, em alguma medida, contemplou as diversas regiões do subespaço do JEB.

Os dados foram coletados e cruzados a partir de diversas fontes primárias e secundárias que forneceram dados qualitativos e quantitativos: questionários, entrevistas - em alguns casos informações diretas por e-mail ou telefone - jornais, livros com biografias, livros do tipo who's who, documentos e verbetes do CPDOC (Centro de Pesquisa e Documentação de História Contemporânea do Brasil), banco de dados da empresa $\mathrm{Ma}$ xpress $^{5}$ e documentos e informações difusas na internet, especialmente sites e arquivos de profissionais, de empresas e de organiza-

mentando, investindo e consumindo: incentivo a importação de papel e maquinários para edição; criação do Ministério das Telecomunicações, da Embratel, da Embrafilme, etc.; expansão da massa consumidora com a urbanização e a escolarização; criação e expansão das emissoras de televisão; expansão da indústria cinematográfica, fonográfica e editorial com livros, jornais, revistas, etc.; expansão dos profissionais correlatos a cada um dos setores da indústria cultural, assim como dos cursos, escolas e universidades para formá-los; expansão da publicidade e propaganda com a vinda de agências multinacionais, com a difusão e ampliação da prática de contratar tais serviços, pelo estado e empresas privadas, e com o enorme fluxo de recursos financeiros que o setor acabou direcionando para as rádios, os jornais e, principalmente, as emissoras de televisão; e um crescente processo de racionalização empresarial, profissionalização, especialização e divisão do trabalho em todos os setores.

4. Relação Anual de Informações Sociais (RAIS); Instituto Brasileiro de Geografia e Estatística (IBGE); Instituto Brasileiro de Opinião Pública e Estatística (IBOPE).

5. Empresa de Serviços de Tecnologia e Informações ou Maxetron. 
ções profissionais - páginas pessoais, Centro de Cultura e Memória do Jornalismo, Portal dos Jornalistas, site Memória Globo, etc.

Procurando respeitar a multiplicidade dos possíveis do subespaço do JEB, e também a ideia de "indivíduos eficientes" (BOURDIEU, 2000) $)^{6}$, foram realizados dois procedimentos.

Primeiro, foi feito um levantamento dos nomes de JE presentes em jornais e revistas de grande tiragem e/ou de circulação nacional ${ }^{7}$ e um levantamento do nome, do e-mail e de alguns dados prosopográficos de cerca de $490 \mathrm{JE}$ que constituem os verbetes de um livro tipo who's who, de Ribeiro e Paschoal (2005), além da consulta a outros livros com biografias, como Abreu e Rocha (2006) e Resende (2005).

Depois, foi introduzida uma questão sobre reconhecimento no questionário. Isto é, foi solicitado aos respondentes que indicassem três nomes de JE que eles consideravam "grandes profissionais". Resultou que 65 nomes foram mencionados, um terço deles mais de uma vez. Foi feito um trabalho sistemático sobre esses nomes, seja enviando e reenvian- do o questionário várias vezes, seja levantando dados sobre eles em outras fontes.

0 questionário foi enviado para $660 \mathrm{JE}$ - para os que tiveram o e-mail identificado - e 65 deles foram preenchidos e devolvidos. A parte da população de JE retida para a ACM é constituída, em sua maioria, por aqueles que responderam aos questionários - os dados foram cruzados e confirmados com outras fontes - e contém indivíduos eficientes e indivíduos oriundos das mais diferentes regiões do espaço: diferentes mídias, veículos, idades, regiões do país.

Foi possível montar 87 prosopografias a partir do cruzamento dos dados. Uma parte delas foi utilizada na ACM. As restantes ficaram no banco de dados e poderão ser completadas e utilizadas em pesquisas e análises subsequentes - no momento, havia dados faltantes ou que não puderam ser confirmados no cruzamento entre as diferentes fontes. Foram analisadas 69 prosopografias com dados pertinentes, conforme a metodologia mobilizada pela pesquisa; a ideia de indivíduos eficientes e a ACM como forma de análise.

6. A ideia de "indivíduos eficientes" é um recurso analítico para chegar às propriedades ativas em um campo via os próprios indivíduos que as detém. Os indivíduos em interação que influenciam efetivamente os processos por que detém alguma propriedade ativa no campo são os indivíduos eficientes, os representantes das forças sociais ativas (BOURDIEU, 2000). No caso dos JE, aqueles reconhecidos nos questionários, entrevistas e declarações dos próprios JE em documentos e textos públicos, especialmente os verbetes e textos dos livros consultados (ABREU e ROCHA, 2006; RESENDE, 2005; RIBEIRO E PASCHOAL, 2005). Esse recurso analítico proporciona também um meio de racionalizar os esforços de pesquisa delimitando as dimensões do levantamento empírico.

7. Foram consultadas as edições de dez jornais e três revistas publicadas durante o mês de fevereiro de 2010: os jornais $O$ Estado de São Paulo, Folha de São Paulo, Valor Econômico, Zero Hora, Brasil Econômico, 0 Estado de Minas, 0 Globo, Jornal de Brasília, Correio Brasiliense, Diário Gaúcho; as revistas Veja, Isto É e Exame. Essas edições possibilitaram o levantamento de nomes de jornalistas que assinaram textos em cadernos de economia, e, em muitos casos, seus respectivos e-mails. Esta parte da pesquisa forneceu nomes de JE atuantes, de fato, naquele momento. Foram escolhidos os jornais e revistas que tinham três características básicas: maior circulação tiragem por edição; circulação nacional principalmente nos Estados de SP, RJ, DF, MG, RS; maior editoria de economia maior número de páginas impressas e de pessoal empregado. 
Cerca de 30 variáveis foram esboçadas: sobre propriedades sociais, trajetória escolar, ocupacional, pertencimento associativo, notoriedade, tomadas de posição a respeito do JEB - sobre os jornalistas, os veículos e conteúdos sobre o que é o JEB - setor da economia que mais cobre, comenta e em que é especializado. Não foram levantadas sistematicamente neste trabalho ${ }^{8}$ variáveis sobre a perspectiva ou o modo de enquadramento da economia - papel do Estado, natureza e prescrições sobre as atividades, relações e agentes econômicos, entre outros - e sobre as fontes de dados, de autoridade para argumentos e de exemplificação para os textos que escrevem.

As informações relativas aos JE foram sistematizadas, cruzadas e confirmadas mutuamente. Mas, na análise, só foram consideradas as variáveis que não tinham dados faltantes. Elas permitiram explorar as relações entre as propriedades sociais, as trajetórias escolar e ocupacional e a notoriedade.

Enfım, foram consideradas 16 variáveis completas para 69 indivíduos. Trata-se de variáveis categóricas não ordenadas e compostas por um número de categorias que varia de dois a oito, sendo 65 no total. As categorias foram definidas a partir de várias análises dos dados, levando em conta dois princípios: que cada uma tivesse um conteúdo exclusivo vis-à-vis outras; e que não representassem menos de 5\% de frequência na constituição da variável - princípio da homogeneidade (LEBARON, 2006; LE ROUX e ROUANET, 2010). Na prática, foram realizadas várias análises de estatís- tica descritiva para chegar ao ajuste final que foi trabalhado pela ACM. Abaixo, as variáveis e suas categorias.

Variáveis sobre as propriedades sociais dos jornalistas. Idade em 2011 (IdAt), com cinco categorias: 20 a 29 anos, 30 a 39 anos, 40 a 49 anos, 50 a 59 anos e 60 a 74 anos. Sexo (Sex), com duas categorias: masculino e feminino. Local de nascimento (LoNa), com três categorias: São Paulo, outras capitais e interior. Escolaridade do pai (EsPa), com quatro categorias: primário completo, fundamental completo, médio completo e superior completo. Ocupação do pai (OcPa), com quatro categorias: trabalho manual, trabalho técnico, trabalho intelectual e empregador.

Variáveis sobre a trajetória escolar dos jornalistas. Ano de formação superior (AnFoSu), com seis categorias: de 1960 a 1969 , de 1970 a 1979 , de 1980 a 1989, de 1990 a 1999 e de 2000 a 2009. E Faculdade em que se formou (Fac), com duas categorias: privada ou púbica.

Um conjunto de variáveis sobre a trajetória ocupacional dos jornalistas. A variável Ano em que iniciou no jornalismo (AnInJo) tem seis categorias: de 1960 a 1969, de 1970 a 1979 , de 1980 a 1989, de 1990 a 1999 e de 2000 a 2009. A variável Veículo em que iniciou no jornalismo (VeInJo) tem oito: Assessoria de imprensa em universidades, órgãos públicos e autarquias, empresas e prefeituras; Jornais e revistas generalistas e pequenos, como Jornal da Tarde, Diário de São Paulo, Diário da Grande ABC, Diário de Pernambuco, Correio Popular de Campinas,

8. Trata-se de variáveis sobre tomadas de posição. Elas não foram levantadas por conta da dimensão do questionário quanto maior menor o número de respostas. Mas foram exploradas em entrevistas e são objetos de pesquisas pontuais em curso (dissertações sobre o Comitê de Política Monetária, o Programa de Aceleração do Crescimento e o Governo de Dilma Rousseff). 
Folha de Pernambuco, Jornal Hoje em Dia, O Estado do Paraná, O Paraná, Jornal Passo a Passo, Jornal do Povo, Jornal do Commercio (Recife, PE), jornais sindicais, e também, Revista Rua Grande, Executivos Financeiros, WebMagazine, Dante Cultural, Arte em São Paulo e Fatos \& Fotos; Jornais generalistas médios: Correio Brasiliense, Notícias Populares, Jornal do Brasil, 0 Estado de Minas e A Tribuna; jornais generalistas grandes: Correio do Povo, Zero Hora e Última Hora; Jornais e revistas generalistas nacionais: 0 Estado de São Paulo, Folha de São Paulo, O Globo e as revistas Veja e Isto É; Jornais e revistas especializados em economia: A Gazeta, Brasil Econômico, Diário Comércio e Indústria, Diário do Comércio, Jornal do Commercio (Rio de Janeiro, RJ), Gazeta Mercantil e, ainda Exame, Globo Rural e Pequenas Empresas Grandes Negócios; Televisão e rádio: TV Bloomberg Television, TV Câmara, TV Gaúcha, TV Gazeta, TV Globo e também Rádio Eldorado, Rádio Jornal de Brasil e Jovem Pan; e Outros como Agência Brasil/Radiobrás, Agência Telenotícia da Revista Visão, InfoMoney e freelance.

A variável Ano em que iniciou no jornalismo econômico (AnInJe) tem seis categorias: de 1960 a 1969, de 1970 a 1979, de 1980 a 1989 , de 1990 a 1999 e de 2000 a 2009. A variável Veículo em que iniciou no jornalismo econômico (VeInJe) tem sete categorias: Jornais e revistas generalistas e pequenos: Jornal da Tarde, Diário de São Paulo, Diário da Grande ABC, Diário de Pernambuco, Correio Popular de Campinas, Folha de Pernambuco, Jornal Hoje em Dia, O Estado do Paraná, O Paraná, Jornal Passo a Passo, Jornal do Povo, Jornal do Commercio (Recife, PE), jornais sindicais e também Revista Rua Grande, Executivos Financeiros, WebMagazine, Dante Cultural, Arte em São Paulo e Fatos \& Fotos; Jornais generalistas médios: Correio Brasiliense, Notícias Populares, Jornal do Brasil, 0 Estado de Minas e A Tribuna; Jornais generalistas grandes: Correio do Povo, Zero Hora e Última Hora; Jornais e revistas generalistas nacionais: 0 Estado de São Paulo, Folha de São Paulo, 0 Globo e também Veja e Isto É; Jornais e revistas especializados em economia: A Gazeta, Brasil Econômico, Diário Comércio e Indústria, Diário do Comércio, Jornal do Commercio (Rio de Janeiro, RJ), Gazeta Mercantil e as revistas Exame, Globo Rural e Pequenas Empresas Grandes Negócios; Televisão e rádio: TV Bloomberg Television, TV Câmara Notícias, TV Gaúcha, TV Gazeta, TV Globo e ainda Radio Eldorado, Rádio Jornal do Brasil, Jovem Pan; e Agências de notícias: Agência Brasil/Radiobrás, Agência Telenotícia da Revista Visão, AgRural Commodities Agrícolas, InvestNews e portal InfoMoney.

A variável Função inicial no jornalismo econômico (FuInJe) tem duas categorias: editor ou redator; repórter ou freelance. A variável Função atual no jornalismo econômico (FuAtJe) tem quatro categorias: uma que engloba proprietários de agência de notícias, colunistas, analistas, comentaristas e repórteres especiais; uma que engloba diretor executivo, diretor de edição e diretor de redação; uma que engloba editor e redator; e uma que engloba repórter e freelance. E a variável Cidade em que trabalha (CiTr) tem cinco categorias: São Paulo; Brasília, Porto Alegre; Recife e outras ${ }^{9}$. Os jornais e revistas foram agrupados em função da dimensão das tiragens diárias, do número

9. Exterior, Campinas, SP, Fortaleza, CE, Rio de Janeiro, RJ, Santo André, SP, Belo Horizonte, MG, Curitiba, PR, Vitória, ES. 
de jornalistas trabalhando na editoria de economia e da amplitude de sua circulação - nacional, regional e local.

Variáveis sobre reconhecimento social ou notoriedade dos jornalistas. Prêmios recebidos durante a carreira (PrRe), com duas categorias: sim e não. Livros publicados (LivrPubl), com duas categorias: sim e não.

Enfim, com os dados possíveis e confiáveis sistematizados, foram feitas as análises estatísticas utilizando o software SPSS Statistics Version 20; primeiro, realizamos várias rodadas de estatística descritiva para ajustar as frequências das categorias das variáveis e, em seguida, a ACM.

\section{A análise estatística e as três gerações}

A ACM, tal como utilizada por pesquisadores franceses, conforme a análise geométrica de dados iniciada por Bénzecri (1992), permite combinar descrição exploratória e relações explicativas (BOURDIEU, 2007; DUVAL, 2004; LEBARON, 2006 e 2009; LE ROUX; ROUANET, 2010; etc.). Ela tem afınidade eletiva com a noção de campo de Bourdieu e, assim, permite construir o espaço social projetando as estruturas de base das prosopografias em um plano fatorial (LEBARON, 2009; LE ROUX e ROUANET, 2010).

A ACM possibilita explorar as estruturas fundamentais dos dados prosopográficos ao resumir em alguns eixos as relações estatísticas presentes no conjunto desses dados. É um tipo de análise em que a quantificação e modelização permitem perceber a dimensão relacional da realidade social. 0 eixo principal do plano fatorial resultante é o que concentra a maior variância ou dispersão; e os subsequentes, os percentuais de variância restantes (LEBARON 2006 e 2009). Geralmente, as interpretações se concentram em um ou dois eixos.
Construir o espaço social é definir as distâncias entre "indivíduos estatísticos" com a ajuda de variáveis ativas. As distâncias entre os indivíduos refletem as dissimilaridades das suas características, captadas pelas dissimilaridades entre as respostas que dão às questões que formam as variáveis - uma só categoria de uma variável. Quanto mais diferentes são, mais distantes estão, e vice-versa. Essas distâncias não são devidas a uma variável particular, mas à interação de todas elas que, somadas, indicam os pontos em que os indivíduos estão. Deste modo, eles são representados sob a forma de nuvem ou subnuvens de pontos em um espaço social multidimensional (LEBARON, 2006; LE ROUX; ROUANET, 2010).

As variáveis utilizadas neste tipo de análise são de dois tipos: as ativas, ou seja, aquelas que contribuem para criar as distâncias entre os indivíduos estatísticos; e as suplementares, que não contribuem para criar as distâncias, mas são projetadas sobre o espaço criado pelas primeiras e, assim, ajudam nas explicações. Geralmente, são variáveis sobre tomadas de posição, com dados incompletos para todos os indivíduos. (LEBARON, 2006; LE ROUX; ROUANET, 2010).

Antes de apresentar a ACM, eis alguns dados numéricos sobre o universo dos JE. De modo geral, eles atuam em diversas mídias: jornal impresso e online, rádio, revista impressa e online, televisão, agências de notícias, portais e blogs na internet. E atuam em cerca de 1220 veículos ou empresas de mídia. Os veículos com maior número de JE atuando em editorias de economia são: Valor Econômico, O Estado de São Paulo, 0 Globo e Folha de São Paulo.

A pesquisa levantou 3359 nomes de JE cruzando todos os dados. Essa informação não é segura, mas é a única que existe. 
Em conclusão, não foi possível encontrar informações precisas sobre a dimensão do número de JE em ação.

Os dois principais resultados da ACM são: as Medidas de Discriminação (Tabela 01) e o Plano Fatorial (Figura 01). As primeiras indicam o peso de cada variável na constituição das duas dimensões do espaço social dos
JE, ou seja, indicam as variáveis que mais contribuíram para produzir a representação do distanciamento social dos jornalistas, expressas, em termos estatísticos, por meio da variância ou da inércia. 0 Plano Fatorial é uma representação gráfica da posição de cada jornalista no espaço social.

Tabela 01 - Medidas de Discriminação

$\begin{array}{lcc}\text { Variável } & \text { Dimensão } 1 & \text { Dimensão 2 } \\ \text { IdAt } & 0,843 & 0,669 \\ \text { Sex } & 0,023 & 0,017 \\ \text { LoNa } & 0,198 & 0,109 \\ \text { EsPa } & 0,118 & 0,298 \\ \text { OcPa } & 0,184 & 0,210 \\ \text { AnFoSu } & 0,869 & 0,788 \\ \text { Fac } & 0,061 & 0,148 \\ \text { AnInJo } & 0,843 & 0,739 \\ \text { VeInJo } & 0,284 & 0,333 \\ \text { AnInJe } & 0,846 & 0,766 \\ \text { VeInJe } & 0,355 & 0,234 \\ \text { FuInJe } & 0,008 & 0,023 \\ \text { FuAtJe } & 0,288 & 0,107 \\ \text { CiTr } & 0,070 & 0,096 \\ \text { PrRe } & 0,055 & 0,000 \\ \text { LivrPubl } & 0,332 & 0,002 \\ \text { Total Ativo } & 5,376 & 4,541 \\ \text { \% da Variância } & 33,599 & 28,379\end{array}$

A análise considerou as variáveis que mais contribuíram com os 33,599\% da variância da primeira dimensão - primeiro eixo - e com os 28,379\% da variância da segunda dimensão - segundo eixo. Quanto maior a contribuição de uma variável com a variância, maior sua contribuição com a formação de um eixo (LE ROUX; ROUANET, 2010).

No que tange à primeira dimensão, foram consideradas as variáveis que tiveram uma contribuição próxima ou acima da média de total ativo $(5,376 / 16=0,336)$. Isto é, seis variáveis contribuíram com os 5,376 de total ativo da primeira dimensão: ano de formação superior $(0,869)$; ano em que ini- ciou no jornalismo econômico $(0,846)$; ano em que iniciou no jornalismo $(0,843)$; idade atual (0,843); veículo em que iniciou no jornalismo econômico $(0,355)$; livros publicados $(0,332)$. Essas variáveis respondem por 4,088 de 5,376, ou seja, 76\% da variância da primeira dimensão.

No que se refere à segunda dimensão, foram consideradas as variáveis que apresentaram uma contribuição próxima ou acima da média $(4,541 / 16=0,284)$. Desse modo, seis variáveis contribuíram com os 4,541 de total ativo da segunda dimensão: ano de formação superior $(0,788)$; ano em que iniciou no jornalismo econômico 
(0,766); ano em que iniciou no jornalismo $(0,739)$; idade atual $(0,669)$; veículo em que iniciou no jornalismo $(0,333)$; e escolaridade do pai $(0,298)$. Essas seis variáveis respondem por 3,593 de 4,541, ou seja, 79\% da variância da segunda dimensão.
Enfım, as duas dimensões analisadas indicam que oito variáveis contribuíram significativamente para diferenciar ou distanciar os jornalistas no espaço social.

0 quadro abaixo apresenta a distribuição dos jornalistas no Plano Fatorial.

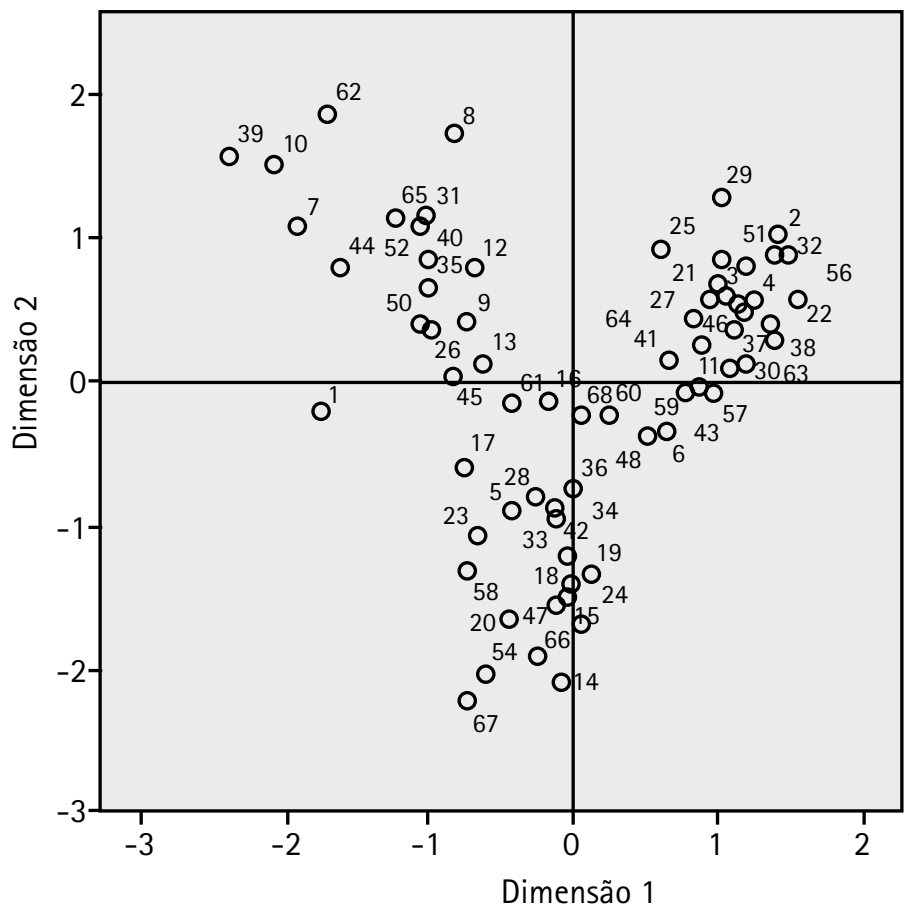

0 dado mais visível são as três subnu-

0 eixo da primeira dimensão tende a sevens de jornalistas. Das seis variáveis que, significativamente, distanciam os jornalistas na primeira dimensão, quatro são as mesmas que os distanciam na segunda dimensão (AnFoSu, AnInJo, AnInJe e IdAt). Isso permite afırmar que o espaço do JEB é estruturado, fundamentalmente, a partir de princípios geracionais: idade, período da formação escolar superior, de entrada no jornalismo e de entrada no JEB. parar a geração intermediária - parte inferior do quadro, predominantemente, no quadrante esquerdo - das gerações mais velha e mais nova - no quadrante superior esquerdo e direito, respectivamente. 0 eixo da segunda dimensão tende a separar a geração mais nova da geração intermediária e, mais acentuadamente, da geração mais velha.

As outras quatro variáveis que contribuíram para distanciar os jornalistas no espaço 
social - duas da primeira dimensão (VeInJe e LivrPubl) e duas da segunda (VeInJo e EsPa) - têm peso relativo menor vis-à-vis às quatro anteriores. Elas indicam que as gerações se diferenciam também em função do veículo de comunicação em que iniciaram a carreira como jornalistas e como JE - especializados ou generalistas, grandes ou pequenos, nacionais ou locais, etc; em função da origem social - maior ou menor escolaridade do pai; e em função do reconhecimento mais geral da sociedade e da indústria cultural - publicação ou não de livros.

Continuando a análise, foram considerados três conjuntos de jornalistas que estão mais demarcadamente distantes no espaço social: jornalistas da subnuvem do quadrante superior direito; da subnuvem do quadrante superior esquerdo; e da subnuvem da parte inferior do quadro, predominantemente no quadrante esquerdo. A partir das características desses jornalistas, serão desdobradas explanações mais precisas sobre os atributos sociais particulares das gerações mais velha, intermediária e mais nova.

À geração mais velha e dominante, pertencem 13 jornalistas da subnuvem do quadrante superior esquerdo: Carlos Alberto Sardenberg (07) ${ }^{10}$, Cecilia Zioni (08), Celso Ming (10), Cida Damasco (12), Gilberto Leal (31) Isabel Dias De Aguiar (35), Joelmir Beting (39), José Paulo Kupfer (40), Luis Nassif (44), Miriam Leitão (50), Nair Suzuki (52), Suely Caldas (62) e Vera Durão (65).

Contraposta a ela, há a geração intermediária com 16 jornalistas, a subnuvem da parte inferior, predominantemente no quadrante esquerdo: Bela Hammes (05), Cleide Silva (14), Cley Scholz (15), Denise Juliani (18), Denise Neumann (19), Denise Zandonadi (20),
Eugênio Esber (23), Fernando Castilho (28), Gustavo Paul Knurrle (33), Helio Paschoal (34), Ivo Ribeiro (36), Liliana Lavoratti (42), Marli Olmos (47), Nelson Rocco (54), Vicente Nunes (66) e Vivaldo De Sousa (67).

E, contraposta a ambas, temos a geração mais nova com 14 jornalistas, a subnuvem do quadrante superior direito: Albert Steinberg (02), Aluisio Alvez (03), Ana Luiza Daltro (04), Elaine Silva (21), Erik Farina (22), Fabiana Parajara (25), Fernanda Pressinott (27), Fernando Jasper (29), Gustavo Kahil (32), João Villaverde (38), Mariana Araujo De Oliveira (46), Mônica Lucas (51) e Rochelli Dantas (56).

\subsection{A geração mais velha}

A geração mais velha é composta por jornalistas que têm algumas características em comum. Por um lado, aquelas descritas pelas quatro variáveis que mais contribuem com a variância: têm de 61 a 69 anos de idade salvo Joelmir Beting, 75 anos, e Miriam Leitão, 58 anos; formaram-se entre 1962 e 1978; iniciaram no jornalismo entre 1966 e 1973 salvo Joelmir Beting, que iniciou em 1957; e a maior parte deles iniciou no JEB quatro ou cinco anos depois, entre 1966 e 1977 - salvo Joelmir Beting, que iniciou em 1962.

Por outro lado, estão as características decorrentes das quatro variáveis que têm menor contribuição com a variância. No que tange ao Veículo em que iniciou a carreira no jornalismo, grande parte dos jornalistas dessa geração iniciou em Jornais e revistas generalistas nacionais (6) - 0 Estado de São Paulo, Folha de São Paulo, 0 Globo e Veja; outra parte iniciou em televisão e rádio (2) - TV Gaúcha e Rádio Jornal do Brasil; em Jornais

10. Localização no Plano Fatorial. 
e revistas generalistas médios (3) - Notícias Populares, A Tribuna e Jornal do Brasil; em Jornais e revistas generalistas grandes (1) Caldas Junior; em Jornais e revistas generalistas pequenos (1) Revista Fatos \& Fotos; e em outros (1) - agência de notícias.

No que se refere ao Veículo em que iniciou a carreira no jornalismo econômico, muitos iniciaram em Jornais e revistas generalistas nacionais (6) - 0 Estado de São Paulo, Folha de São Paulo e Veja. Outra parte iniciou em outros (3) - agências de notícias; em Jornais e revistas generalistas grandes (1) - Zero Hora; em Jornais e revistas generalistas pequenos (1) - Revista Fatos \& Fotos; e em Jornais e revistas especializados em economia (1) - Gazeta Mercantil.
Quanto à Publicação de livros, parte (6) publicou um ou mais. E, em relação à Escolaridade do pai, há um bom indicador de origem social. Considerando essa variável juntamente com a variável Ocupação do $p a i-4,6 \%$ de contribuição com a variância da segunda dimensão; a origem social dos jornalistas fica menos obscura: uma parte (5) tem pai com escolaridade superior e ocupação intelectual ou empregadora - advogado, farmacêutico, industriário, empresário agrícola; outra parte (5), com ensino médio e ocupação intelectual ou empregadora - presidente de empresa, capitão das Forças Armadas e empresário; e outra parte (3) com ensino fundamental e ocupação empregadora - comerciante. 


\section{Joelmir Beting}

Filho de pequeno comerciante com escolaridade fundamental completa, nasceu em Tambaú, SP, em 1936. Formou-se em Ciências Sociais pela Universidade de São Paulo em 1962. Em 1957, iniciou no jornalismo como repórter, redator e comentarista em jornais esportivos - $O$ Esporte e Diário Popular - e na rádio Pan-Americana (Jovem Pan). Iniciou no jornalismo econômico em 1962, como redator de estudos de viabilidade econômica para projetos desenvolvidos por uma consultoria de São Paulo e, em 1966, foi contratado pelo jornal Folha de São Paulo. Foi repórter, editor, colunista, comentarista, apresentador e âncora. Em sua trajetória, passou por diversos veículos de comunicação: jornais O Esporte, Diário Popular, Folha de São Paulo e $O$ Estado de São Paulo (O Globo reproduzia sua coluna); rádios Pan-Americana, Gazeta, Bandeirantes, Excelsior e CBN; e canais de televisão Gazeta, Record, Bandeirantes e Globo. Em 1973, publicou o livro Na Pratica, a Teoria é outra, e, em 1985, publicou Juros Subversivos, entre outros. Uns dos destaques de sua carreira foi ter lançado a editoria de automóveis no caderno de classificados do jornal Folha de São Paulo, ainda em fins dos anos 1960. Em 1970, lançou sua coluna diária no mesmo jornal. Ela o acompanhou quando ele foi para $O$ Estado de São Paulo em 1991, e era publicada por inúmeros jornais brasileiros até seu fim em 2004. E, finalmente, ficou conhecido por relatar assuntos da vida econômica contornando o "economês" e utilizando a linguagem e o estilo de comentarista de futebol; de modo simples, direto, usando metáforas, trocadilhos e humor. Recebeu vários prêmios de jornalismo, como o Esso, o Comunique-se, o Apimec-MG e o Grande Prêmio Instituto Ayrton Senna. Desde 2000, mantinha seu site próprio sobre análise macroeconômica e ministrava palestras para empresas, universidades, etc. Faleceu em novembro de 2012.

\section{Suely Caldas}

Filha de comerciante com escolaridade fundamental completa, nasceu em Belém, PA, em 1944. Em 1967, formou-se em Jornalismo pela Universidade Federal do Rio de Janeiro. Ainda em 1966, iniciou no jornalismo como estagiária no jornal $O$ Globo. Em 1973, estreou no jornalismo econômico na agência de notícias Telenotícias, da Revista Visão. Em sua trajetória, passou pelos jornais O Jornal, O Globo, Folha de São Paulo, O Estado de São Paulo, Gazeta Mercantil e Jornal do Brasil. Trabalhou nas revistas Visão e Exame e na $T V$-Educativa. Foi repórter, redatora, chefe de redação, diretora de sucursal, debatedora e colunista. Em 2003, publicou o livro Jornalismo Econômico. Um dos destaques de sua trajetória foi ter realizado reportagens de base investigativa e com rigor na apuração. Por exemplo: a reportagem "PP/Collor, a Grande Farsa”, sobre corrupção na Petrobras em 1992, precedendo as denúncias de Pedro Collor à Veja e o subsequente impeachment de Fernando Collor; e a manchete de $O$ Estado de São Paulo "Operações fantasmas minaram Nacional", que expôs a falência latente do Banco Nacional em 1996 dada a existência de milhares de contas fantasmas em suas operações contábeis. Recebeu vários prêmios de jornalismo, dentre os quais dois Esso - um para cada uma das reportagens citadas. Ministra palestras em seminários e congressos organizados por sindicatos, associações empresariais e universidades, inclusive no exterior. Atualmente, é colunista de economia do jornal $O$ Estado de São Paulo.

Fonte: elaboração do autor a partir das fontes da pesquisa 
Em sintese, alguns atributos principais tendem a caracterizar os jornalistas dessa geração: eles têm de 61 a 69 anos de idade; formaram-se de início dos anos 1960 a fins dos anos 1970; iniciaram no jornalismo de meados dos anos 1960 ao início dos anos 1970 e iniciaram no JEB alguns anos depois, já durante o regime militar (1964-1985). Trata-se de uma geração que foi recrutada nos estratos sociais médios, urbanos, escolarizados e, de modo geral, tem uma origem social elevada, considerando-se que, no período após a Segunda Guerra Mundial, era raro ter escolaridade superior, ou mesmo ensino médio, e ocupação intelectual - e o status e a distinção deles decorrentes.

Essa geração tem um núcleo "duro" de jornalistas que iniciaram no jornalismo e no JE nos grandes jornais e revistas generalistas paulistanos. Eles se caracterizam também por terem ampliado a participação na indústria cultural, isto é, reconvertido o reconhecimento acumulado no espaço jornalístico para o mercado editorial, para o espaço empresarial e para o espaço das consultorias - publicação de livros, propriedade de empresas de mídia, realização de palestras e conferências para empresários, banqueiros, investidores, universitários, etc.

\subsection{A geração intermediária}

A geração intermediária é composta por jornalistas que têm algumas características em comum. Por um lado, as características descritas pelas quatro variáveis que têm maior contribuição com a variância: idade entre 45 e 59 anos; formação entre 1979 e 1989; início no jornalismo entre 1975 e 1987; e início no JE um pouco mais tarde, entre 1982 e 1994. Parte começou a carreira já no JE e parte entrou no JE somente cinco ou seis anos depois.
Por outro lado, há as características decorrentes das quatro variáveis que têm menor contribuição com a variância. Em relação ao veículo em que iniciou a carreira no jornalismo, grande parte iniciou em jornais e revistas generalistas pequenos (11) - Diário do Grande $\mathrm{ABC}, 0$ Estado do Paraná, Revista Rua Grande, Jornal do Povo, Jornal Correio Popular, 0 Paraná, Jornal do Commercio (Recife, PE) e jornais sindicais e de bairro. Outra parte iniciou em jornais e revistas especializados em economia (3) - Diário Comércio e Indústria, A Gazeta, e Jornal do Commercio (Rio de Janeiro, RJ); em assessoria de imprensa (1) - universidade pública; e em jornais e revistas generalistas pequenos (1) - Caldas Junior.

No que tange ao veículo em que iniciou a carreira no jornalismo econômico, grande parte iniciou em jornais e revistas especializados em economia (7) - Diário Comércio e Indústria, A Gazeta, Jornal do Commercio (Rio de Janeiro, RJ) e Gazeta Mercantil; outros iniciaram em jornais e revistas generalistas nacionais (3) - 0 Estado de São Paulo, Veja, Isto É; em jornais e revistas generalistas pequenos (3) - Diário do Grande $\mathrm{ABC}$; em jornais e revistas generalistas médios (2) - Jornal do Brasil; e em jornais e revistas generalistas grandes (1) - Correio do Povo.

Já com relação à publicação de livros, grande parte deles não publicou, somente dois. Em relação à escolaridade do pai, há um bom indicador de origem social. Considerando essa variável juntamente com a variável ocupação do pai - 4,6\% de contribuição com a variância da segunda dimensão - a origem social dos jornalistas ganha contornos: uma parte tem pai com escolaridade superior e ocupação intelectual (6) - jornalista, gerente, médico, juiz e engenheiro; outra parte com o ensino médio e ocupação intelectual ou técnica (4) - professor, super- 
visor de usinagem e alfaiate; outra parte (5) com escolaridade primária e ocupação manual ou empregadora - motorista, operário, agricultor, pedreiro e comerciante; e uma parte com ensino fundamental e ocupação empregadora (1) - comerciante.

Quadro 2: Duas biografias ilustrativas da geração intermediária

\section{Vicente Nunes}

Filho de comerciante com escolaridade primária completa, nasceu em Guaratinguetá, SP, em 1965. Formou-se em Jornalismo pela Universidade Gama Filho, RJ, em 1989. Em 1987, iniciou no jornalismo como jornalista de economia, no cargo de repórter do Jornal do Commercio (Rio de Janeiro, RJ). Em sua trajetória, já foi repórter, repórter especial, editor-chefe, colunista, correspondente internacional e editor de economia. Passou por diversos jornais: Jornal do Commercio (Rio de Janeiro, RJ), O Globo, Jornal do Brasil, Correio Brasiliense, Agência Estado e Gazeta Mercantil. Atualmente, é editor de economia do jornal Correio Braziliense. Recebeu, individual e coletivamente, alguns prêmios de jornalismo: CNH, AMB, Imprensa Embratel e Esso.
Denise Zandonadi

Filha de agricultor com escolaridade primária completa, nasceu em Venda Nova do Imigrante, ES, em 1959. Formou-se em jornalismo pela Universidade Federal do Espírito Santo em 1981. Em 1982, iniciou no jornalismo como jornalista de economia, no cargo de repórter do jornal A Gazeta de Vitória, ES. Em sua trajetória, foi repórter, subeditora, editora adjunta, produtora, assessora de imprensa e repórter especial. Sempre trabalhou na empresa $A$ Gazeta como jornalista de economia, no jornal e na rádio. Também trabalhou na assessoria de imprensa da Secretaria Estadual de Comunicação do Espírito Santo, e como assessora de imprensa da TV Educativa e da Rádio Espírito Santo. Recebeu por duas vezes o Prêmio Capixaba de Jornalismo. Atualmente, é repórter de economia da empresa $A$ Gazeta.

Fonte: elaboração do autor a partir das fontes da pesquisa.

Em sintese, eis os atributos principais que tendem a caracterizar essa geração: são jornalistas que têm de 45 a 59 anos de idade e se formaram nos anos 1980; iniciaram a carreira no jornalismo de meados dos anos 1970 a meados dos anos 1980, sendo que uma parte já iniciou no JE e outra iniciou no JE cinco ou seis anos mais tarde. Tal geração foi recrutada tanto nos extratos sociais médios, urbanos e escolarizados, quanto em extratos sociais mais baixos. $\mathrm{Ou}$ seja, é de origem social mais mista, pois conta com indivíduos de origem social mais modesta do que os da geração mais velha. Ainda comparando com a geração anterior, esses jornalistas apenas iniciaram a reconversão do reconhecimento oriundo do meio jornalístico para o mercado editorial - mais uma atuação na indústria cultural.
Outros atributos também tendem a caracterizar essa geração. Ela estreou profissionalmente de modo diferente e mais diversifıcado vis-à-vis à geração anterior. Diferentemente dos mais velhos, uma parte desses jornalistas começou em jornais e revistas generalistas pequenos e em jornais e revistas especializados em economia. Os que migraram para o JE seguiram duas vias: permaneceram no próprio jornal ou partiram para jornais e revistas generalistas nacionais.

\subsection{A geração mais nova}

A geração mais nova é composta por jornalistas que têm algumas características em comum. Por um lado, aquelas descritas pelas quatro variáveis de maior peso na variância: têm de 24 a 39 anos de idade; 
formaram-se entre 1998 e 2009; iniciaram no jornalismo entre 1998 e 2006; e a maior parte deles iniciou no JE dois ou três anos depois, entre 2000 e 2008.

Por outro lado, as características decorrentes das quatro variáveis que têm menor contribuição com a variância. No que tange ao veículo em que iniciou a carreira no jornalismo, uma parte dos jornalistas dessa geração começou em assessoria de imprensa (5) - empresa e órgãos públicos; uma parte em jornais e revistas especializados em economia (3) - A Gazeta, Gazeta Mercantil e Diário Comércio e Indústria; uma parte em outros (3) - portais e agências de notícias online como portal It Web, AgRural Commodities Agrícolas; outra parte em rádio e televisão (1) - TV Câmara Notícias; e outra em jornais e revistas pequenos (1) Revista Executivos Financeiros.

Quanto ao veículo em que iniciou a carreira no jornalismo econômico, parte iniciou em jornais e revistas especializados em economia
(5) - A Gazeta, Diário Comércio e Indústria e Exame; parte em outros (3) - portais e agências de notícias online como InvestNews, InfoMoney e AgRural Commodities Agrícolas; parte em jornais e revistas generalistas pequenos (3) Jornal Folha de Pernambuco; parte em jornais e revistas generalistas nacionais (1) - 0 Estado de São Paulo; e parte em rádio e televisão (1) - TV Globo.

No que se refere à publicação de livros, nenhum deles publicou. E, em relação à escolaridade do pai, há um bom indicador de origem social. Considerando essa variável junto com a variável ocupação do pai-4,6\% de contribuição com a variância da segunda dimensão -, a origem social dos jornalistas fica mais nítida: uma parte tem pai com escolaridade superior e ocupação intelectual (8) - urbanista, arquiteto, bancário, bioquímico farmacêutico, engenheiro e médico; outra parte (5) com ensino médio e ocupação empregadora ou técnica - vendedor, construtor, comerciante e técnico em eletrônica.

Quadro 3: Duas biografias ilustrativas da geração mais nova

\section{Rocheli Dantas}

Filha de arquiteto com escolaridade superior, nasceu em Recife, PE, em 1987. Formou-se em jornalismo pela Faculdades Integradas Barros Melo de Recife, PE, em 2008. Iniciou na Comunicação Social em 2005 como assessora de imprensa em prefeitura (Recife, PE). Iniciou no jornalismo econômico em 2008, como repórter de economia do jornal Folha de Pernambuco de Recife, PE. Em sua trajetória, foi assessora de imprensa, repórter, subeditora e colunista. Atuou, como assessora de imprensa, em prefeitura (Recife, PE), autarquia estadual e empresa privada e, como jornalista, no jornal Folha de Pernambuco e Diário de Pernambuco. Atualmente, é repórter de economia no jornal Diário de Pernambuco.

\section{João Villaverde}

Filho de publicitário com escolaridade superior, nasceu em São Paulo, SP, em 1987. Formou-se em jornalismo pela Pontifícia Universidade Católica de São Paulo, SP, em 2009. Iniciou no jornalismo em 2006, como jornalista de economia, no cargo de repórter de economia do jornal Diário Comércio e Indústria de São Paulo. Em sua trajetória, foi repórter, colunista de edição para iPad, repórter setorista e blogueiro. Passou por alguns jornais: Diário Comércio e Indústria de São Paulo, Valor Econômico e $O$ Estado de São Paulo. E participou esporadicamente de programas, como Fatos e Versões, da Globo News, Tribuna Independente, da Rede Vida, e Observatório da Imprensa, da TV Brasil. Possui um blog sobre economia e variedades. Atualmente, é repórter de economia do jornal O Estado de São Paulo na sucursal de Brasília.

Fonte: elaboração do autor a partir das fontes da pesquisa. 
Em sintese, a geração mais nova tem de 24 a 39 anos de idade, formou-se e iniciou no jornalismo no final dos anos 1990 e durante os anos 2000 e, em sua maior parte, iniciou no JE dois ou três anos depois, entre 2000 e 2008. É oriunda dos estratos sociais médios, urbanos e escolarizados. Em grande medida, tem origem social menos modesta que a geração anterior e menos elevada que a primeira geração, dada a ausência de pai com escolaridade primária e ocupação manual, e dado que escolaridade superior e ocupação intelectual nos anos 1980 não conferiam a mesma distinção e status que conferiam nos anos após a Segunda Guerra Mundial.

Outros atributos também tendem a caracterizar essa geração. Ela iniciou a carreira de modo mais diversificado que as anteriores, pois, além de ter começado no jornalismo e no JE em jornais e revistas especializados em economia, como a geração anterior e diferentemente da primeira geração, iniciou no jornalismo em assessoria de imprensa e em portais e agências de notícias online, e também iniciou no JE em portais e agências de notícias online e em jornais e revistas generalistas pequenos.

Por fım, além das diferenças, há características que os jornalistas de todas as gerações compartilham. Por exemplo: iniciaram como repórter, a maioria não trabalhou no exterior e, durante a carreira, circularam por diversos jornais - passaram por mais de três jornais ou revistas, no mínimo. Grande parte dos jornalistas das duas gerações mais novas reconhecem alguns dos jornalistas da geração mais velha como os "grandes profıssionais". Isso permite afırmar que os jornalistas da geração mais velha são os dominantes no espaço do JEB, pois, além desse reconhecimento, eles trabalham predominantemente como âncoras, comenta- ristas, analistas, colunistas e repórteres especiais dos principais veículos - TV Globo, Rádio CBN e 0 Estado de São Paulo, ou seja, aqueles que têm maior equipe empregada em editoria de economia e maior tiragem ou audiência. Além disso, os jornalistas da geração mais velha possuem empresas de mídia, equipes de jornalistas próprias, blogs e portais. Encontramos profissionais em tais posições nas outras gerações, mas nelas tende a predominar jornalistas nas funções de redator, editor, repórter, direção, direção executiva e chefia.

E, finalmente, podemos afirmar também que a ascensão na ocupação implica em iniciar, ascender e circular pelos grandes jornais e revistas paulistas e investir em passagens pela televisão e rádio.

\section{Considerações finais}

Em linhas gerais, a análise apresentou a morfologia do espaço do JEB e explorou os principais atributos de ordem geracional, escolar, origem social e, especialmente, ocupacional que a ACM permitiu visualizar como os que mais contribuem para distanciar os jornalistas distribuídos nesse espaço. Destes fatores, decorreram revelações sobre as hierarquias e os trunfos sociais que possibilitam ascender e permanecer em posições dominantes.

A análise trouxe diversas explanações sociológicas sobre o estado do espaço do JEB a partir de algumas de suas dimensões. Outras dimensões desse espaço podem ser reveladas na medida em que for possível acessar dados e formar novas variáveis. Por exemplo, dados sobre outras ocupações além de JE, sobre as relações com o Estado, mais detalhamento a respeito da escolaridade e da formação intelectual - perspectivas sobre a economia - sobre a relação 
com as fontes - quais, como e em que circunstâncias. E, por fim, vale considerar que outras dimensões do espaço do JEB poderiam ser reveladas, incluindo variáveis sobre tomadas de posição, ou seja, análises comparativas dos produtos simbólicos dos jornalistas em diferentes posições - objeto de pesquisas em curso.

\section{Referências}

ABREU, A. A. Jornalistas e jornalismo econômico na transição democrática. In: ABREU, A. A.; LATTMAN-WELTMAN, F.; KORNIS, M. A. Mídia e Política no Brasil: jornalismo e ficção. Rio de Janeiro: Editora FGV, 2003.

ABREU, A. A.; ROCHA, D. Elas ocuparam as redações: depoimentos ao CPDOC. Rio de Janeiro: Editora FGV, 2006.

BENZECRI, J. P. Correspondence analysis handbook. New York: Marcel Dekker, 1992.

BOURDIEU, P. 0 mercado dos bens simbólicos. In: BOURDIEU, P. A Economia das trocas simbólicas. São Paulo: Perspectiva, 1987a.

. Campo do poder, campo intelectual e habitus de classe. In: BOURDIEU, P. A Economia das Trocas Simbólicas. São Paulo: Perspectiva, 1987b.

Sobre o poder simbólico. In: BOURDIEU, P. 0 poder simbólico. Rio de Janeiro: Bertrand Brasil, 1989.

L'emprise du journalisme. Actes de la Recherche em Sciencies Sociales. no 101, 1994.

As regras da arte. São Paulo: Companhia das Letras, 1996.

Le champ économique. Actes de la Recherche em Sciencies Sociales, no 119, 1997.

Les structures sociales de l'économie. Paris: Seul, 2000.

. A distinção: crítica social do julgamento. São Paulo/Porto Alegre: Edusp/Zouk, 2007.

CALDAS, S. 2003. Jornalismo econômico. São Paulo: Contexto, 2003.
CHAMPAGNE, P. Le journalisme à l'économie. Actes de la Recherche em Sciencies Sociales, $\mathrm{n}^{\circ}$ 131-132, 2000.

CHAMPAGNE, P. L'étude des médias et l'apport de la notion de champ. In: PINTO, É. Pour une analyse critique des médias: le débat public en danger. Paris: Éditions du Croquant, 2007.

DUVAL, J. Critique de la raison journalistique. Paris: Le Seuil, 2004.

GOFFMAN, E. Frame analysis: an essay on the organization of experience. Cambridge: Harvard University Press, 1974.

KUCINSKI, B. Jornalismo econômico. São Paulo: Edusp, 1996.

LE ROUX, B. ROUANET, H. Multiple correspondence analysis. London: Sage, 2010.

LEBARON, F. L'enquête quantitative en sciences sociales. Paris: Dunor, 2006.

How Bourdieu "quantified" Bourdieu: the geometric modelling of data. In: ROBSON, K. SANDERS, C. (Orgs.). Quantifying theory: Pierre Bourdieu. Toronto: Springer, 2009.

LENE, H. 0 jornalismo econômico e a reinvenção do Brasil no final do século XX. Tese de doutorado. Programa de Pós-Graduação da Escola de Comunicação. Universidade Federal do Rio de Janeiro, 2009.

MARTINS, L. Estado capitalista e burocracia no Brasil pós-64. Rio de Janeiro: Paz e Terra, 1985.

NASSIF, L. 0 jornalismo dos anos 90. São Paulo: Futura, 2003.

ORTIZ, R. A moderna tradição brasileira. São Paulo: Brasiliense, 1988.

QUINTÃ0, A-S. F. 0 jornalismo econômico no Brasil depois de 1964. Rio de Janeiro: Agir, 1987.

RESENDE, J. V. Construtores do jornalismo econômico: da cotação do boi ao congelamento dos preços. São Paulo: Ícone, 2005.

RIBEIRO, E. PASCHOAL, E. Jornalistas brasileiros: quem é quem no jornalismo de economia. São Paulo: Mega Brasil e Call Comunicações, 2005. 
RIUTORT, P. Le journalisme au service de l'economie. Actes de la Recherche em Sciencies Sociales, no 131-132, 2000.

ROBSON, K. SANDERS, C. (Orgs.). Quantifying theory: Pierre Bourdieu. Toronto: Springer, 2009.
SCHUDSON, M. The power of news. Cambridge, Mass: Harvard University Press, 1995.

SKIDMORE, T. Brasil: de Castelo a Tancredo. Rio de Janeiro: Paz e Terra, 1988.

\section{RESUMO}

Este artigo apresenta uma objetivação do espaço dos jornalistas de economia brasileiros. Para isso, foi realizada uma análise de correspondências múltiplas de 69 prosopografias de jornalistas atuantes durante 2011. São apresentadas as fontes de dados, as variáveis, suas categorias e o conteúdo correspondente. A análise demonstra que esse espaço é estruturado, fundamentalmente, a partir de princípios geracionais e que, atualmente, três gerações nele convivem. Por fim, demonstra as características específicas de cada geração vis-à-vis outras.

\section{PALAVRAS-CHAVE}

Jornalismo econômico. Sociologia da comunicação. Mídia. Análise de correspondências múltiplas. Sociologia econômica.

\section{ABSTRACT}

This article presents an objectification of the space occupied by Brazilian economic journalists. To this, a multiple correspondence analysis of 69 prosopographies of active journalists during 2011 was realized. The data source, the variable, its categories and the correspondent content are presented. The analysis demonstrates that this space is structured fundamentally from generational principles and that, nowadays, three generations coexist. Finally, it demonstrates the specific characteristics of each generation vis-à-vis anothers.

\section{KEYWORDS}

Economic journalism. Sociology of communications. Media. Multiple correspondence analysis. Economic sociology. 